\title{
A IMPORTÂNCIA DOS TÉCNICO-ADMINISTRATIVOS EM EDUCAÇÃO DO CAMPUS RIO POMBA DO IF SUDESTE MG NA CONSOLIDAÇÃO DO ENSINO MÉDIO INTEGRADO ATRAVÉS DA GESTÃO DEMOCRÁTICA-PARTICIPATIVA
}

\author{
THE IMPORTANCE OF ADMINISTRATIVE TECHNICIANS IN EDUCATION \\ OF IF SUDESTE MG CAMPUS RIO POMBA IN THE CONSOLIDATION \\ OF INTEGRATED HIGH SCHOOL THROUGH DEMOCRATIC PARTICIPATORY \\ MANAGEMENT
}

\author{
FURTADO, Eniete de Oliveira Campos ${ }^{1}$ \\ MACHADO, Alex Fernandes da Veiga ${ }^{2}$ \\ SOUZA, Helton Nonato de ${ }^{3}$
}

\section{RESUMO}

Este artigo trata da importância dos técnico-administrativos em educação na gestão democrática participativa como uma das formas de consolidação do ensino médio no Campus Rio Pomba do IF Sudeste MG. Para tanto, esses servidores, gestores e trabalhadores em educação participam de órgãos colegiados e assumem funções gratificadas e cargos de direção, necessitam ocupar esses, e outros espaços, de forma consciente amparados pelas bases da educação profissional e tecnológica e dos objetivos dos Institutos Federais de Educação, Ciência e Tecnologia. Nesse intuito o artigo traz esclarecimentos sobre os conceitos de gestão-democrática participativa, gestão educacional e gestão escolar. Trata da participação do técnico-administrativo enquanto trabalhador em educação na gestão do Campus Rio Pomba e dos seus espaços de participação democrática.

Palavras CHAVes: Ensino médio integrado; Gestão-democrática participativa; Técnico-administrativos em educação.

\footnotetext{
1 Instituto Federal de Educação, Ciência e Tecnologia do Sudeste de Minas Gerais (IF SUDESTE MG) / Programa de Mestrado Profissional em Educação Profissional e Tecnológica (ProfEPT). Rio Pomba, MG, Brasil. e-mail: enietefurtado@gmail.com

2 Instituto Federal de Educação, Ciência e Tecnologia do Sudeste de Minas Gerais (IF SUDESTE MG) / Programa de Mestrado Profissional em Educação Profissional e Tecnológica (ProfEPT). Cataguases, MG. Brasil. e-mail: alex.machado@ifsudestemg.edu.br

${ }^{3}$ Instituto Federal de Educação, Ciência e Tecnologia do Sudeste de Minas Gerais (IF SUDESTE MG) / Programa de Mestrado Profissional em Educação Profissional e Tecnológica (ProfEPT). São João del Rei, MG, Brasil. e-mail: helton.nonato@ifsudestemg.edu.br
} 
DOI: $10.12957 / \mathrm{e}-\mathrm{mosaicos} .2020 .46442$

\section{ABSTRACT}

This article deals with the importance of technical and administrative civil servants in the participatory democratic management as one of the forms of consolidating the high school at the Rio Pomba Campus of IF Sudeste MG. To this they participate in collegiate bodies, assume rewarded functions and leadership positions. They need to occupy these and other spaces, consciously supported by the bases of professional and technological education and the objectives of the Federal Institutes of Education, Science and Technology. The article shows an insight into the concepts of participatory democratic management, educational management and school management. It deals with the participation of technical and administrative workers in education in the management of the Rio Pomba Campus and its spaces for democratic participation.

KEYWORDS: integrated high school; participatory democratic management; technical and administrative workers in education.

\section{INTRODUÇÃO}

Os servidores técnico-administrativos em educação (TAEs) dos Institutos Federais de Educação, Ciência e Tecnologia (IFs), de acordo com seu plano de Carreira, exercem vários cargos no ambiente escolar. Como exemplo, pode-se citar: Bibliotecário, Pedagogo, Administrador, Engenheiro, Técnico em Laboratório, Técnico em Agropecuária, Assistente em Administração, Assistente de Alunos, dentre outros (BRASIL, 2005).

Através destes cargos, se conectam e interagem com várias atividades que abrangem todos os setores dos IFs onde são desenvolvidas atividades permanentes ligadas ao ensino, à pesquisa, à extensão e à administração. Esses servidores também podem ser investidos temporariamente em cargos de direção ou funções gratificadas de chefia, conforme consta no regime jurídico dos servidores públicos civis da União, das autarquias e das fundações públicas (BRASIL, 1990).

Assim, esses servidores, para além de funcionários de escola, são de acordo com Monlevade (2001) mais que cidadãos e profissionais, são também gestores e educadores. De acordo com Leão (2009, p. 314) a "... educação não se dá apenas na sala de aula, mas em outros espaços em que também são transmitidos saberes e valores fundamentais na formação para a cidadania".

Portanto, trataremos da gestão democrática-participativa com enfoque na importância do papel profissional da atuação com qualidade dos TAEs, nos diversos espaços de atuação profissional. Focaremos no sentido de propiciar uma reflexão sobre a importância e valorização dos que atuam no espaço cotidiano de trabalho e contribuem para organização e a gestão do Campus Rio Pomba do IF Sudeste MG e consolidação do ensino médio integrado. 
DOI: $10.12957 /$ e-mosaicos.2020.46442

\section{REVISITANDO CONCEITOS IMPORTANTES}

Antes de abordar o papel dos TAEs na gestão democrática-participativa enquanto trabalhadores em educação e educadores, primeiro é necessário que alguns conceitos e fundamentos teóricos, ligados ao assunto, sejam esclarecidos.

Para Freitas (2000), não foi por acaso que durante muito tempo as escolas adotaram o modelo de administração científica de Taylor, que se constituía no modelo da sociedade industrial do início do XX, centralizadora e hierarquizada. Essa maneira de administrar atingiu a escola influenciada pelo modo de produção capitalista, onde "a gerência propicia o controle do capital" (CARVALHO, 2016, p. 86). é:

De acordo com Chiavenato (1983 apud CARVALHO, 2016, p. 85), administrar

[...] interpretar os objetivos propostos pela organização e transformálos em ação organizacional através do planejamento, organização, direção e controle de todos os esforços realizados em todas as áreas e em todos os níveis da organização, a fim de alcançar tais objetivos da maneira mais adequada à situação.

Desse modo, extrai-se que as políticas educacionais no Brasil, principalmente as que foram adotadas nos meados finais de 1990, foram responsáveis por significativas mudanças na forma de gestão da escola. O termo gestão pode ser utilizado para designar atividades administrativas, quando se remete a origem do termo que vem do latim gero, gestume, gerere que significa chamar para si, executar, gerar. Assim pode se compreender que o termo gestão tem uma abrangência maior que o sentido de comando, designando uma forma de administrar através do diálogo e com envolvimento do coletivo (CARVALHO, 2016).

Continuando o raciocínio, Carvalho o autor apresenta o termo gestão como uma mudança de paradigma, pois expressa mais que a substituição do termo administração, ele passa a expressar a sua superação. Assim gestão pode se constituir como ação conjunta de trabalho participativo em equipe.

Uma vez esclarecido os termos administração e gestão cabe agora um esclarecimento sobre gestão educacional e gestão escolar. Na Constituição Federal, art. 205, a educação é posta como um "direito de todos e dever do Estado e da família" Brasil (1988). A constituição também garante o acesso ao ensino público e gratuito, garantia de um valor público, que para se efetivar necessita de políticas que se operacionalizam através da gestão.

Gestão educacional se refere aos sistemas educacionais e se expressa nas esferas ensino federal, estadual e municipal, como esfera macro; enquanto a gestão escolar, por sua vez, se refere aos estabelecimentos de ensino, esfera micro. A escola 
DOI: $10.12957 / \mathrm{e}-\mathrm{mosaicos} .2020 .46442$

e o trabalho realizado nela são a razão da existência da gestão educacional, enquanto a gestão escolar deve orientar-se para promover o ensino e aprendizagem (VIEIRA, 2007).

Com relação às atividades que são consideradas próprias da gestão educacional, Carvalho (2016) cita o financiamento, a organização, o planejamento, a avaliação institucional, ou seja, orientações e formulações gerais que dão consistência à política educacional. Logo, cabe à gestão escolar, no nível micro, o cuidado para com atividades desenvolvidas pelos profissionais das escolas, tais como: elaboração do projeto político-pedagógico, organização do calendário escolar, avaliação do aluno, dentre outras.

Já a gestão democrática, muito discutida entre os educadores, tem sua base legal na Constituição de 1988, art. 206, inciso VI, que define a "gestão democrática do ensino público, na forma da lei" Brasil (1988) e na Lei de Diretrizes e Bases da Educação Nacional (LDB), Lei 9.394/96, art. 30, inciso VIII "gestão democrática do ensino público, na forma desta Lei e da legislação dos sistemas de ensino" (BRASIL, 1996).

[...] o modelo democrático-participativo tem sido influenciado por uma corrente teórica que compreende a organização escolar como cultura. [...] Em outras palavras, dizer que a organização escolar é uma cultura significa que ela é construída pelos seus próprios membros (LIBÂNEO, 2001, p.3).

Dourado (2012), entretanto, ressalta que a efetivação da gestão depende da mobilização das comunidades escolares e locais, articuladamente com os trabalhadores em educação.

\section{GESTÃO DEMOCRÁTICA-PARTICIPATIVA E OS TAES, ENQUANTO TRABALHADORES EM EDUCAÇÃO DOS IFS E O ENSINO MÉDIO INTEGRADO}

No sistema capitalista, a escola enquanto organização social contribui tanto para a manutenção do modo de produção, como para sua superação, uma vez que é constituída por relações contraditórias estabelecidas entre os grupos sociais de interesses antagônicos. A possibilidade de a gestão escolar propiciar uma educação capaz de transformar a sociedade, por meio desenvolvimento da participação cidadã, demonstra como a própria contradição leva a escola a um trabalho emancipatório. (DOURADO, 2012).

Os IFs têm como um importante objetivo, a oferta o ensino médio integrado à educação profissional (EMI) em que deve garantir no mínimo $50 \%$ de suas vagas para oferta da educação técnica de nível básico prioritariamente na forma integrada 
DOI: $10.12957 /$ e-mosaicos.2020.46442

(BRASIL, 2008). A modalidade de ensino médio oferecido nestas instituições apresenta em sua gênese uma proposta voltada para transformação social, a partir da análise, do reconhecimento e da transformação da realidade local.

Para Ciavatta (2005, p. 2):

A formação integrada sugere tornar íntegro, inteiro, o ser humano dividido pela divisão social do trabalho entre a ação de executar e a ação de pensar, dirigir ou planejar. [...] Como formação humana, o que se busca é garantir ao adolescente, ao jovem e ao adulto trabalhador o direito a uma formação completa para a leitura do mundo e para a atuação como cidadão pertencente a um país, integrado dignamente à sua sociedade política. Formação que, neste sentido, supõe a compreensão das relações sociais subjacentes a todos os fenômenos.

Desse modo, os TAEs enquanto trabalhadores em educação de uma instituição que tem o EMI como um dos principais objetivos, devem considerar a relevância do espaço onde atuam. Para Ciavatta (2005) o exercício da formação integrada não é autoritário, mas uma experiência de democracia participativa.

De acordo com Dourado (2012) para a escola se tornar um espaço formativo significativo de formação dos sujeitos, é preciso compreender as concepções que a norteiam e a importância da organização dos espaços e os tempos pedagógicos e a dinâmica da participação na gestão e construção de uma educação de qualidade.

Assim, de com Vieira (2007, p.63), algumas atividades se expressam, notadamente, pois:

[...] se inscrevem no campo da gestão escolar, de modo específico aquelas que envolvem a tarefa cotidiana de ensinar e aprender. Nesta esfera da gestão, situam-se professores, alunos e outros membros da comunidade escolar - funcionários que trabalham na escola, docentes que ocupam cargos diretivos, famílias e integrantes da área de abrangência geográfica onde localiza a escola.

Segundo Monlevade (2012) os funcionários são educadores que se preocupam com a gestão material da educação na escola. "Não pode ser desprezada essa "materialidade" porque se trata dos canais por onde fluem as atividades de ensinoaprendizagem" (MONLEVADE, 2012, p.84).

Para Dourado (2012) é importante que esses trabalhadores não-docentes conheçam a legislação e a escola em que trabalham e os mecanismos de participação democrática. Por exemplo, a Lei $11.982 / 08$ que cria os Institutos Federais de 
DOI: $10.12957 /$ e-mosaicos.2020.46442

Educação, Ciência e Tecnologia, traz no seu texto a educação profissional técnica de nível médio, prioritariamente na forma de cursos integrados (BRASIL, 2008).

Já a Lei 11.091/05, que institui o plano de carreira dos técnico-administrativos em educação das instituições federais de ensino, no seu artigo 30, item I diz que a gestão desses cargos deve observar como um dos princípios e diretrizes a "natureza do processo educativo, função social e os objetivos do Sistema Federal de Ensino" (BRASIL, 2005).

E ainda segundo a LDB, no seu art. 14,

Os sistemas de ensino definirão as normas da gestão democrática do ensino público na educação básica, de acordo com as suas peculiaridades e conforme os seguintes princípios: I - participação dos profissionais de educação na elaboração do projeto político pedagógico da escola; II - participação das comunidades escolar e local em conselhos escolares ou equivalentes (BRASIL, 1996).

A LDB, como se pode perceber, e de acordo com Vieira (2007), oferece ampla autonomia às unidades federadas para a operacionalização da gestão democrática do ensino público na educação básica, em sintonia com suas especificidades. Isso porque "a autonomia passou a se constituir a palavra de ordem para a construção de uma escola democrática" (MARANHÃO E MARQUES, 2014, p. 129).

Para Vieira (2007, p. 62), "a autonomia de uma escola não é algo espontâneo, mas construído a partir de sua identidade e história". Enquanto que para Ciavatta (2005, p.13) "a identidade que cada escola e seus professores, gestores, funcionários e alunos constroem é um processo dinâmico, sujeito permanentemente à reformulação relativa às novas vivências, às relações que estabelecem."

No entanto, a gestão democrática, de acordo com Vieira (2007) tem sido muito discutida entre os educadores e se constituído num grande desafio na operacionalização das políticas de educação e no dia a dia da escola.

Portanto, para que a gestão democrática possibilite a construção de um currículo com base na realidade local com melhoria do processo educacional, qualidade pedagógica e apoio à comunidade precisa de maior integração dos professores, diretores, estudantes e técnico-administrativos como participantes ativos do processo de desenvolvimento do trabalho escolar (DOURADO, 2012).

\section{EsPaÇOS dE PARTICIPAÇÃo demOCRÁtICA dOS TAEs do CAMPUS RIO POMBA}

As instituições escolares necessitam de uma estrutura de organização interna, geralmente prevista no Regimento Interno ou em legislação específica, conforme 
Libâneo (2001), estrutura, aqui no sentido de disposição e ordem de funções para assegurar o funcionamento da escola.

Veiga (1998, apud DOURADO, 2012, p.88) esclarece que a escola possui dois tipos básicos de estrutura, a administrativa e a pedagógica. A administrativa relacionase à gestão e a alocação de recursos humanos, físicos e financeiros. A pedagógica refere-se a questões de ensino aprendizagem e as de currículo escolar.

Os TAEs lotados no Campus Rio Pomba participam dessas duas estruturas. Assim eles se constituem como trabalhadores em educação, que de acordo com Dourado (2012), sendo docentes e não-docentes contribuem para que a escola cumpra seu papel primordial de formação dos estudantes e daqueles que nela trabalham e a constroem.

A estrutura de organização interna, prevista em Regimento Interno ou em legislação específica, é necessária em toda instituição escolar, e conforme Libâneo (2001), estrutura aqui no sentido e disposição do ordenamento das funções que asseguram o funcionamento da escola, representada graficamente por meio de um organograma.

Com relação à estrutura organizacional, relativa aos cargos de direção e funções gratificadas que são remuneradas, o organograma do Campus Rio Pomba é composto pela Direção Geral seguida hierarquicamente por cinco diretorias: Diretoria de Administração, Diretoria de Desenvolvimento Institucional, Diretoria de Ensino, Diretoria de Extensão e Diretoria de Pesquisa e Pós-Graduação. Hierarquicamente abaixo, das diretorias seguem oito cargos de direção (CD04). Em seguida, respectiva e hierarquicamente, têm-se as funções gratificadas (FG 01) num total de (treze) e em seguida as funções (FG 02, FG 03) num total de dezenove.

Se agruparmos didaticamente em quatro grupos as funções e cargos de direção, teremos o seguinte percentual de TAEs no organograma do Campus Rio Pomba: cargos de direção geral e diretorias, $16,6 \%$, cargos de direção (CD4) 62,5\%, funções gratificadas (FG01) 84,6\% e funções gratificadas (FG02 e FG 03) 55,5\%.

Estes percentuais, calculados a partir de dados fornecidos em agosto de 2019 pela Coordenação de Gestão de Pessoas do Campus Rio Pomba, mostram a participação quantitativa dos técnico-administrativos que é bastante significativa proporcionalmente para as funções que compõem o organograma do Campus.

A gestão de uma escola não é isolada da função educativa e nem do processo ensino-aprendizagem. E que professores e funcionários, incluindo diretor e sua equipe são todos, educadores e gestores, "porque a gestão, hoje, não é uma atividade-meio, ela é intrinsecamente pedagógica" (MONLEVADE, 2001, p.77).

A gestão democrática é entendida como a participação efetiva dos vários segmentos da comunidade escolar, pais, professores, 
DOI: $10.12957 /$ e-mosaicos.2020.46442

estudantes e funcionários, na organização, na construção e avaliação dos projetos pedagógicos, na administração dos recursos da escola, enfim, nos processos decisórios da escola. Portanto, tendo mostrado as semelhanças e diferenças da organização do trabalho pedagógico em relação a outras instituições sociais, enfocamos os mecanismos pelos quais se pode construir e consolidar um projeto de gestão democrática na escola (DOURADO, 2012, p.91).

A implantação de órgãos colegiados na escola, com diversas funções, inclusive a de zelar pela qualidade do ensino e pela transparência dos recursos da escola, de acordo com Freitas (2000) pode ser um espaço de decisões e participações coletivas voltadas para o interesse das comunidades escolar e local.

Para a autora os órgãos colegiados e conselhos escolares são constituídos por representantes de professores, de técnico-administrativos, de alunos, de pais e diretor, que muitas vezes não receberam orientação adequada ou não desenvolveram de forma integral a competência, ou desconhecem seu papel como legítimos representantes da vontade de seus pares.

A participação dos TAEs nas instâncias colegiadas do Campus Rio Pomba do IF Sudeste MG se faz presente, dentre outras, através da participação no Conselho de Campus, "órgão consultivo e deliberativo que tem a finalidade de colaborar para o aperfeiçoamento do processo educativo e zelar pela correta execução das políticas do IF no Campus Rio Pomba" (Campus Rio Pomba, 2019).

Para Ciavatta e Ramos (2011) as dificuldades para a implantação da formação integrada pode ser superada através de um projeto que supere os padrões pedagógicos conservadores, as posições políticas contrárias à educação emancipatória e que "tenha base na crítica à sociedade de mercado, gestão e participação democrática nas instituições educacionais, estudos e qualificação conceitual..." (CIAVATTA e RAMOS, 2011, p.36).

Dourado (2012) ressalta a importância do papel dos trabalhadores nãodocentes, denominados "funcionários da educação" e destaca a importância destes conhecerem a legislação, os processos de trabalho, a escola em que atuam, os mecanismos de participação e decisão, os ritos e processos decisórios, os documentos institucionais e a sua produção, fundamentais para vivência da gestão democrática. Para o autor, a gestão democrática se faz através de participação coletiva e se efetiva através de instâncias colegiadas de caráter consultivo e/ou deliberativo, na escolha de dirigentes e na construção do projeto político-pedagógico (PPP), dando plena garantia através da participação de todos os segmentos da comunidade.

O processo de organização educacional precisa de instrumentos de ação para atingir os objetivos que de acordo com Libâneo (2001) são planejamento, organização, direção/coordenação, formação continuada e avaliação. Em muitas escolas tais 
instrumentos são elaborados de forma a se ampliar a participação comunitária, em outras não. Entretanto a memória institucional, ou seja, a memória e a participação dos TAEs consistem em importante contrapartida para o desenvolvimento de muitas ações.

Tomando como exemplo Veiga (1998), a elaboração do projeto políticopedagógico é uma ação muito importante para a comunidade escolar e deve ser considerado como um processo permanente de reflexão e discussão dos problemas da escola, incentivando todos a participarem. A busca de alternativas viáveis para efetivar sua intencionalidade, propiciar a vivência democrática-participativa para que todos os membros da comunidade escolar possam exercer sua cidadania e a coerência com os arranjos produtivos locais são fatores que atenuam a elaboração de planos e projetos inexequíveis e/ou efêmeros.

Nesse sentido, considerando que os PPPs dos cursos técnicos integrados do Campus Rio Pomba estão sendo revisados por uma Comissão específica responsável por esta atividade nota-se a participação de dois técnico-administrativos (Campus Rio Pomba, 2019).

Logo, se a identidade da escola é um processo dinâmico construído pelos seus professores, gestores, alunos e funcionários, em permanente reformulação de acordo com novas vivências e relações restabelecidas, toda ação é efetivamente um instrumento de modificação do ambiente escolar, que pode colaborar com avanços ou retrocessos na medida em que acontecem. Desse modo, "destaca-se a importância de as escolas produzirem, dentro de suas realidades e de forma participativa, os seus próprios currículos e propostas político pedagógicas" (CIVATTA, 2005, p.9).

\section{Novos ESPAÇOS A OCUPAR, NOVAS FORMAS DE ATUAR}

O EMI, segundo Araújo e Frigotto (2015), é um projeto que traz um conteúdo político pedagógico comprometido com a transformação social e os conteúdos não são concebidos na perspectiva imediatista do mercado, e sim, com referência as necessárias transformações sociais. É nesta fase da formação humana que os sujeitos deparam com os primeiros mecanismos de controle, de administração de recursos, de manutenção da ordem, de monitoramento da eficiência, da eficácia e da efetividade das ações a que estão atrelados. Há que despertar, tanto nestes sujeitos, quanto na comunidade acadêmica, a importância da participação individualizada e amplamente representada.

De acordo com Bezerra (2017) uma das ameaças ao futuro dos IFs pode ser:

A ausência de um diálogo mais reflexivo sobre a nova concepção, as diretrizes e os objetivos dos IFETs junto aos servidores das antigas Escolas Técnicas Federais (ETFs) e às unidades dos Cefets, os quais 
DOI: $10.12957 / \mathrm{e}-\mathrm{mosaicos} .2020 .46442$

vieram a constituir-se em IFETs, e também nas recentes unidades implantadas, o que na prática configurou apenas uma assimilação de alguns procedimentos formais; sem, contudo, alterar o modus operandi em relação à pesquisa e à extensão, muitas vezes, desassociadas e, muitas vezes, direcionadas, preferencialmente, ao setor produtivo, com pouco direcionamento para outros segmentos sociais (BEZERRA, 2017, p. 370).

Um dos obstáculos que EMI tem que enfrentar é a carência de "formação inicial e continuada dos servidores (sejam, técnico-administrativos em educação e/ou docentes para a prática do integrado)" Marçal e Ribeiro (2017, p. 247). Colocam os autores que fundamentalmente importante é existirem reuniões contínuas, espaços e momentos de encontros coletivos, para se planejar e construir o ensino médio integrado. Adicionalmente, a participação é uma conquista, porém, registra-se muitas vezes não se ter tal percepção, ou quando a comunidade é chamada a participar, nem sempre ela está preparada para uma ação que promova de fato alguma transformação (MARANHÃO e MARQUES, 2014).

Assim, da mesma forma que muitos profissionais da educação desconhecem sua importância no processo de construção de uma escola, também os TAEs do Campus Rio Pomba devem procurar se inteirar mais melhor sobre os objetivos dos IFs, o EMI, as bases conceituais da educação profissional e tecnológica (EPT). Hipotetizase que uma vez tendo esses conceitos solidificados e incorporados na práxis cotidiana pode-se aliar a teoria à prática e qualificar melhor a participação dos envolvidos em processos e espaços democráticos.

Desse modo, podem trazer suas contribuições de forma consciente e em consonância com uma proposta de educação integral e cidadã. A concepção de que todos que trabalham numa escola participam da formação do cidadão/cidadã precisa ser entendida e vivenciada.

Portanto, de acordo com Leão (2009), é importante que os funcionários ocupem seus espaços, participem de debates e mostrem o ponto de vista de quem não está em sala de aula, mas também exercem atividade que educa. Para Moura (2007) uma das proposições para a organização curricular do ensino médio integrado é capacitação permanente de docentes, gestores e técnico-administrativos.

As atividades dos TAES não podem ser alienadas com relação à formação omnilateral dos sujeitos que chegam para a escola e precisam ser executadas de forma coerente com a proposta fundamental dos IFs. Só assim poderão contribuir para a solidificação do EMI no Campus Rio Pomba e ajudar a formar cidadãos capazes de construírem a sua história, fazerem a diferença, intervindo de forma consciente nas suas vidas e na sociedade. 
DOI: $10.12957 /$ e-mosaicos.2020.46442

\section{CONCLUSÃo}

Os TAEs têm uma participação significativa na gestão do Campus Rio Pomba do IF Sudeste MG, instituição da Rede Federal de Educação Profissional, Científica e Tecnológica, que tem o ensino médio integrado como um grande objetivo. No entanto precisam ocupar qualitativamente os espaços existentes e estarem preparados para utilizarem outros espaços de participação.

Para isso ainda que seja necessário buscar capacitação com relação às bases da EPT e os objetivos dos IFs. Assim, esses trabalhadores em educação poderão ter uma participação consciente e mais efetiva na gestão do Campus Rio Pomba e de reconhecida importância por toda a comunidade, interna e externa.

Quando se fala de uma formação integrada, todos dentro da escola, não só professores e estudantes, precisam estar comprometidos e atuantes, assumindo o seu papel para que o ensino médio integrado se consolide como política de Estado e não de governo e que promovam de fato as transformações profissionais e sociais tendo referência os sujeitos que nele atuam diretamente e que dele também são beneficiários.

\section{REFERÊNCIAS}

BRASIL. Constituição da República Federativa do Brasil de 1988. Diário Oficial da República Federativa do Brasil. Brasília, DF, 05 Out. 1988. Disponível em http://www.planalto.gov.br/ccivil 03/constituicao/constituicao.htm. Acesso em: 01 jun. 2019.

. Lei 8.112/90 de 11 de dezembro de 1990.Dispõe sobre o regime jurídico dos servidores públicos da União, das autarquias e das fundações públicas federais. Diário Oficial da União. Brasília, DF,12 Dez. 1990. Disponível em: http://www.planalto.gov.br/ccivil 03/leis/l8112cons.htm. Acesso em: 26 jun. 2019.

. Lei 9.394, de 29 de dezembro de 1966. Estabelece as diretrizes e bases da educação nacional. Diário Oficial da União, Brasília, DF, 23 Dez. 1996. Disponível em: http://www.planalto.gov.br/ccivil 03/leis/19394.htm. Acesso em: 10 jun.2019.

. Lei 11.892, de 29 dezembro de2008.Institui a Rede, e dá outras Federal de Educação Profissional, Científica e Tecnológica, cria os Institutos Federais de Educação, Ciência e Tecnologia providências. Diário Oficial da União, Brasília, DF, 30 dez. 2008. Disponível em: htpp://www.planalto.gov.br/ccivil_03/_Ato2007.../Lei/L11892.htm. Acesso em 26 jun. 20189 
DOI: $10.12957 /$ e-mosaicos.2020.46442

. Lei 11.091, de 12 de janeiro de 2005.Dispõe sobre a estruturação do Plano e Carreira dos Técnico-Administrativos em Educação, no âmbito das Instituições Federais de Ensino vinculadas ao Ministério da Educação, e dá outras providências. Diário Oficial da União, Brasília, DF, 13 Jan. 2005. Disponível em: http://www.planalto.gov.br/ccivil 03/ ato2004-2006/2005/lei/l11091.htm. Acesso em 26 jun. 2019.

ARAUJO, R.L., FRIGOTTO, G. Práticas pedagógicas e ensino integrado. Revista Educação em Questão, Natal, v.52, n.38, p.61-68, maio/ago.2015. Disponível em: file:///C:/Users/Usuario/Downloads/7956-Texto\%20do\%20artigo-20820-2-1020170418.pdf. Acesso em: 26 jun. 2019.

BEZERRA, Fábio Aparecido Martins. Institutos Federais: inovação, contradições e ameaças em sua curta trajetória. Ensino médio integrado no Brasil: fundamentos, práticas e desafios/ Adilson César Araújo e Cláudio Nei Nascimento da Silva (orgs.) Brasília: Ed. IFB, 2017. 569 p. vários autores. Disponível em:

http://www.anped.org.br/sites/default/files/images/livro completo ensino medio int egrado - 1310 2017.pdf. Acesso em: 03 out. 2019.

Campus Rio Pomba. Disponível em: https://www.ifsudestemg.edu.br/riopomba. Acesso em: 01 set. 2019.

CARVALHO, Elma Júlia Gonçalves de. Política e Gestão da Educação: explorando o significado dos termos. Série-Estudos, Campo Grande, MS, v. 21, n.41, p.77-96, jan./abr.2016. Disponível em: http://www.serie-estudos.ucdb.br/index.php/serieestudos/article/view/945. Aceso em: 01 jun. 2019.

CIAVATTA, Maria. A Formação integrada: a escola e o trabalho como lugares de memória e identidade. Trabalho necessário. Ano 3, número 3, 2005. Disponível em http://periodicos.uff.br/trabalhonecessario/article/view/6122/5087. Acesso em 01 jun.. 2019.

CIAVATTA, M.; RAMOS, Ensino Médio e Educação Profissional no Brasil Dualidade e Fragmentação. Revista Retratos da Escola, Brasília, v. 5, n. 8, p. 27-41, jan./jun. 2011. Disponível em:

http://retratosdaescola.emnuvens.com.br/rde/article/viewFile/45/42. Acesso em: 03 out. 2019.

DOURADO, Luiz Fernando. Gestão em Educação Escolar. Rede e-tec. Brasil. 40.ed. Cuiabá, Universidade Federal do mato Grosso, Rede e-tec, Brasil, 2012 Ministério da Educação, secretaria de Educação Profissional e Tecnológica. Disponível em: http://portal.mec.gov.br/index.php?option=com docman\&view=download\&alias=33 
DOI: $10.12957 / \mathrm{e}-\mathrm{mosaicos} .2020 .46442$

461-02-disciplinas-form-pedagogica-caderno-06-gestao-em-educacao-escolarpdf\&category slug=fevereiro-2016-pdf\&Itemid=30192. Acesso em 1 jun.2019.

FERNANDES, Francisco das Chagas. Organização e valorização dos funcionários. Cenário Atual e Desafios. In: Revista Retrato da Escola, Brasília, v.3, n.5, p.313-323, jul./dez. 2009. Disponível em: file:///C:/Users/Usuario/Downloads/25-735-1-PB.pdf. Aceso em: 1 jun. 2019

FREITAS, Katia Siqueira. Uma inter-relação: políticas públicas, gestão democráticoparticipativa na escola pública e formação da equipe escolar. Em aberto. Brasília, DF, v.17, n.72, p. 47-59, fev./jun. 2000. Disponível em: file:///C:/Users/Usuario/Downloads/2118-2178-1-PB.pdf. Acesso em: 1 jun. 2019.

LEÃO, Roberto Franklin. Organização e valorização dos funcionários. Cenário Atual e Desafios. In: Revista Retrato da Escola, Brasília, v.3, n.5, p.313-323, jul./dez. 2009. Disponível em: file:///C:/Users/Usuario/Downloads/25-735-1-PB.pdf. Aceso em: 01 jun. 2019.

LIBÂNEO, José Carlos. O sistema de Organização e Gestão da Escola. In: LIBÂNEO, José Carlos. Organização e Gestão da Escola - teoria e prática. $4^{a}$ ed. Goiânia: Alternativa, 2001. Disponível em: https://acervodigital.unesp.br/bitstream/123456789/32/3/LDB Gest\%C3\%A3o.pdf. Acesso em: 01 jun.2019.

MAGALHÃES, Caroline Stéphanie Campos Arimatéia. Trabalho educativo do técnicoadministrativo do IFRN/CNAT: consensos e dissensos. Natal, RN, 2016. Dissertação apresentada ao Programa de Pós-Graduação em Educação Profissional (PPGEP) do Instituto Federal de Educação, Ciência e Tecnologia do Rio Grande do Norte. Disponível em:https://memoria.ifrn.edu.br/bitstream/handle/1044/1389/Caroline\%20Stéphanie \%20-\%20TRABALHO\%20EDUCATIVO\%20DO\%20TÉCNICOADMINISTRATIVO\%20DO\%20IFRNCNAT CONSENSOS\%20E\%20DISSENSOS.pdf?sequence $=1$ \&isAllowed $=y$ Acesso em: 02 abr. 2019.

MARANHÃO, I.M.L; MARQUES, L.R. Os Mecanismos de Participação na Escola: instrumentos de gestão democrática ou controle? Espaço do Currículo. V.7,n.1,p.125136, jan.-abr. 2014. ISSN 1983-1579.Texto.

MARÇAL, F; RIBEIRO, J. A. R. O Ensino Integrado no IFRS e seus potenciais de enfrentamento a dualidade. Ensino médio integrado no Brasil: fundamentos, práticas e desafios/ Adilson César Araújo e Cláudio Nei Nascimento da Silva (orgs.) - Brasília: Ed. IFB, 2017. 569 p. vários autores. Disponível em: 
DOI: $10.12957 /$ e-mosaicos.2020.46442

http://www.anped.org.br/sites/default/files/images/livro completo ensino medio int egrado - 1310 2017.pdf. Acesso em: 03 out. 2019.

MONLEVADE, Antônio Cabral. Funcionários de Escolas: cidadãos, educadores, profissionais e gestores. Rede e-tec. Brasil. 40.ed. Cuiabá, Universidade Federal do Mato Grosso, Rede e-tec, Brasil, 2012 Ministério da Educação, Secretaria de Educação Profissional e Tecnológica. Disponível em: http://portal.mec.gov.br/index.php?option=com docman\&view=download\&alias=33 411-02-disciplinas-form-pedagogica-caderno-01-funcionarios-de-escola-cidadaoseducadores-profissionais-e-gestores-pdf\&category slug=fevereiro-2016pdf\&Itemid=30192. Acesso em: 01 jun. 2019.

MOURA, Dante Henrique. Educação básica e educação profissional e tecnológica: dualidade histórica e perspectivas de integração. Holos, ano 23, vol.2, 2007. p. 4-30.

VEIGA, Ilma Passos da. Projeto Político-Pedagógico da escola: uma construção coletiva. In: VEIGA, IIma Passos da (org.). Projeto político-pedagógico da escola: uma construção possível. Campinas: Papirus, 1998. p. 11-35. Disponível em: https://www.sinprodf.org.br/wp-content/uploads/2014/01/PPP-segundo-IImaPassos.pdf. Acesso em: 10 jun. 2019.

VIEIRA, Sofia Lerche. Política(s) e Gestão da Educação Básica: revisitando conceitos simples. RBPAE. v. 3, n.1, p.53-69, jan./abr.2007. Disponível em: https://seer.ufrgs.br/rbpae/article/viewFile/19013/11044. Acesso em: 01 jun. 2019.

Recebido em 04 de novembro de 2019 Aceito em 27 de maio de 2020

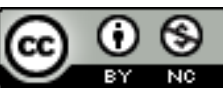

A e-Mosaicos Revista Multidisciplinar de Ensino, Pesquisa, Extensão e Cultura do Instituto de Aplicação Fernando Rodrigues da Silveira (CAp-UERJ) está licenciada com uma Licença Creative Commons - Atribuição-NãoComercial 4.0 Internacional.

Os direitos autorais de todos os trabalhos publicados na revista pertencem ao(s) seu(s) autor(es) e coautor(es), com o direito de primeira publicação cedido à e-Mosaicos.

Os artigos publicados são de acesso público, de uso gratuito, com atribuição de autoria obrigatória, para aplicações de finalidade educacional e não-comercial, de acordo com o modelo de licenciamento Creative Commons adotado pela revista. 